\title{
ÉTICA CIVIL Y ÉTICA RELIGIOSA EN ESPAÑA
}

\section{CIVIL AND RELIGIOUS ETHICS IN SPAIN}

\author{
Antonio Alaminos Chica alaminos@ua.es \\ Universidad de Alicante. España.
}

Clemente Penalva Verdú clemente.penalva@ua.es

Universidad de Alicante. España.

\begin{abstract}
RESUMEN
Se muestra la existencia en España de una ética civil, coherente con el proceso de secularización y modernización experimentado por las sociedades europeas. Tras una exposición de las bases conceptuales de lo que se considera "ética civil", y empleando los datos de la encuesta internacional Pew Global Attitudes Project, se contrastan un conjunto de hipótesis para España relativas al peso de factores estructurales (sexo, edad, educación e ideología) en la aceptación de una ética cívica o religiosa, y la influencia de esta en opiniones, actitudes y comportamientos relacionados con la religión en la vida pública. El contraste empírico de las hipótesis especificadas revela la influencia que tiene la opción ética en la opinión pública referida al Estado, la sociedad y la religión. Los resultados son acordes con los expuestos por investigaciones anteriores, validándolos, al emplear expresiones alternativas y permitiendo un análisis novedoso de la ética civil y religiosa en la sociedad española.
\end{abstract}

\section{Palabras Clave}

Modelo estructural; Multiculturalidad; Religión; Secularización; Valores.

\section{Abstract}

This study shows the existence of a civil ethics in Spain, consistent with the process of secularisation and modernisation experienced by European societies. Following a discussion of what "civil ethics" are actually based on, using data from the international Pew Globes Attitudes Project survey, a series of hypotheses for Spain are contrasted concerning the weight of structural factors (sex, age, education and ideology) in the acceptance of a civic or religious ethics; and its influence on opinions, attitudes and behaviors related to religion in public life. The empirical analysis of the specified hypotheses reveals the influence that the ethical option exerts on public opinion with regard to the State, society and religion. The results are consistent with those obtained in previous research, and are validated by using alternative phrasing and allowing for innovative analysis of civil and religious ethics in Spanish society.

\section{KEYWORDS}

Multiculturalism; Religion; Secularisation; Structural Model; Values. 


\section{LA SECULARIZACIÓN EN EsPaÑa}

El proceso de secularización, como fenómeno sociológico, fue definido principalmente por Weber y Durkheim, quienes lo situaban en el centro de sus construcciones teóricas sobre la sociedad. Weber (1987) observaba cómo las diferentes esferas de la experiencia se independizaban de la esfera religiosa. La religión quedaba marginada de la vida pública, tras un proceso en el cual la progresiva racionalización del mundo sustituye las explicaciones de origen mágico y sobrenatural de la vida social por especulaciones más acordes a un contexto sociocultural basado en la ciencia y la racionalidad instrumental. Para Durkheim (1982) el proceso de secularización consistiría no tanto en una desaparición de lo sagrado (conjunto de ritos y creencias asociados a lo extraordinario) sino en una transformación en la cual los símbolos teístas son sustituidos por símbolos laicos, puesto que lo sagrado no desaparece, y cumple unas funciones sociales de integración social que son necesarios para toda vida social. Los sentimientos y las experiencias que se asocian a los ritos tendrían formas distintas y darían lugar al surgimiento de una religión de carácter civil ${ }^{1}$.

En ambos casos, la presencia de la religión, en su faceta de explicación y legitimación del orden social, o como fuente teológica de creencias y ritos de integración, quedaría desplazada. La fuerza de estos argumentos, que están íntimamente vinculados a la teoría de la modernización, ha dado lugar a un importante desarrollo teórico de lo que se ha llamado "tesis de la secularización". Tesis que está siendo debatida en los últimos tiempos. Con Esteban (2008), podemos presentar los extremos de la discusión sobre la tesis de la secularización: si es un fenómeno universal o únicamente occidental; si es consustancial a la modernización o puede desligarse de ella; si altera o no el comportamiento de la misma religión -haciéndola más mundana y preocupándose más del bienestar de los individuos que de su salvación-; si solamente se produce allí donde la religión no es necesaria para mantener la identidad de grupo; y si es únicamente válida para las sociedades con un importante dominio histórico en los ámbitos político y cultural de la religión, pero no para sociedades con religiones más mundanas o laicas, como es el caso del confucionismo chino.

Como indica Casanova (en Esteban 2008:310-311), la discusión se debe a una confusión entre los tres significados a los que alude el término secularización (diferenciación de la religión respecto a los ámbitos seculares político y económico; declive de las creencias y prácticas religiosas; y desplazamiento de lo religioso hacia lo privado). La tesis que este trabajo desarrolla es que estas tres dimensiones están estrechamente vinculadas y son coherentes. La coherencia se ve reflejada en la ubicación de la población española con respecto a un conjunto de asuntos incluidos en la encuesta Pew Global Attitudes Project cuyos datos analizamos. El análisis del conjunto

\footnotetext{
${ }^{1}$ Un trabajo en el cual se estudia cómo el nacionalismo ocupa el lugar de la religión en el proceso de secularización es el de Santiago (2005).
} 
de ítems que la encuesta propone da como resultado dos imágenes diferenciadas pero coherentes en su composición, formadas por las actitudes hacia la religión como fuente de valores morales y su relación con la política, así como por las prácticas religiosas y las concepciones acerca del mundo. Dos imágenes cuyos elementos configuradores instituyen lo que supondría una "ética civil" de base secular, contrapuesta a una "ética religiosa" con fuentes de valor relacionados con las creencias basadas en lo trascendente y sobrenatural.

No obstante, la fotografía realizada en un momento determinado no puede ser observada aislada de su contexto, en el sentido de observar la secularización, tal como ha sido definida teóricamente y a la luz de la información disponible, como un proceso histórico. La sociedad española, como la mayoría de las sociedades del contexto europeo, ha experimentado un proceso de secularización (con evidentes periodos de retroceso) desde finales del siglo XIX. Una secularización expresada mediante la pérdida progresiva de influencia de la religión en la vida social, política y cultural. Mientras que la secularización política supone la pérdida del papel de la religión en lo institucional o público; la secularización de lo social y cultural refleja un cambio de mentalidad, en las costumbres y las prácticas sociales, donde la religión es sustituida por otras fuentes de valor. El desarrollo de una ética civil en España se produce en un contexto de pérdida de creyentes, una disminución del número de católicos practicantes y un descenso del peso de los principios católicos; así como una opinión mayoritaria contraria a la influencia de la Iglesia en los asuntos públicos.

Multitud de estudios muestran empíricamente este "proceso lento pero persistente" (González Blasco 2002) de secularización de la sociedad española (Jiménez Blanco y Estruch 1972; Giner y Sarasa 1992; Castón 2002; González-Anleo 2006; Díaz Salazar 2007; Pérez-Agote 2007; Elzo 2008a y 2008b). Una secularización que ha producido cambios, desde las formas de religiosidad hasta el desapego de los creyentes hacia la Iglesia. Su falta de adaptación a los cambios en las costumbres ha dado como resultado el desarrollo entre los católicos de una "religiosidad centrífuga" (Arroyo 2005). Sin embargo, este proceso se ha caracterizado por haber sufrido rupturas y retrocesos, como el periodo de la dictadura de Franco. La sociedad española presentaba hace más de un siglo un antagonismo constante como efecto del peso de la religión en la vida social, política y cultural. Un conflicto entre la secularización laica y los proyectos de restauración religiosa (Cueva 2007). Frente al papel histórico de la Iglesia como administradora de la creencia en un dogma, veladora del correcto comportamiento y vinculada al poder político y económico; surgió el anticlericalismo librepensador, valorizador de la educación y preocupado por la pobreza y las desigualdades sociales. Una correspondencia política clara (derecha e izquierda, respectivamente) que se debe matizar en términos históricos. Aunque la burguesía soslayaba la lucha contra las desigualdades, mantenía su carácter reformista defendiendo propuestas orientadas a reducir la influencia de la Iglesia católica en la política, en tanto que elemento anacrónico que impedía la modernización. Así se expresó en la Guerra Civil donde las fuerzas democráticas liberales quedaron ubicadas en el bando republicano. El resultado fue un colapso en el proceso modernizador. El 
franquismo instauró las señas de identidad del nuevo régimen a partir de la fusión ideológica y política del Estado con la religión católica. El vínculo entre los ciudadanos -homogeneizados a través de la idea de España indivisible- y la doctrina eclesiástica se materializó en el nacionalcatolicismo. Este encerró en la idea de patria tanto la pertenencia a un territorio y a un Estado, como la pertenencia a una religión; e incorporó el catolicismo como rasgo de identidad, adquirido desde su origen por el nacimiento y por el bautismo: la necesidad de ser católico para poder ser un auténtico español. Las referencias a la libertad religiosa en el marco legislativo del régimen reflejan su identificación con la religión católica y una escasa tolerancia al resto de confesiones. La Ley de Libertad Religiosa de 1967 fue una adaptación legislativa como respuesta a los cambios doctrinales de la Iglesia a partir del Concilio Vaticano II. Su promulgación, como respuesta a las presiones diplomáticas, proporcionó una imagen de apertura al régimen y permitió el registro de otras confesiones. Una ligera modificación (con importantes limitaciones al culto fuera del templo y a la creación de instituciones educativas y sociales) que hizo superar las trabas administrativas y la vigilancia policial derivada de la escasa tolerancia religiosa presente en el Fuero de los Españoles de 1945; pero que no satisfizo ni al resto de confesiones ni a los sectores más inmovilistas del régimen y de la Iglesia. Como indica Moreno (2001:363) este debate sobre libertad religiosa manifestó la actitud defensiva de la Iglesia católica, su división interna y la identificación de las posiciones oficiales del régimen y del episcopado.

Esta posición defensiva de la Iglesia frente al pluralismo y a la continua secularización de la sociedad explicaría el papel privilegiado que el Estado otorga a la religión católica en los sucesivos textos legales (Constitución de 1978 y Ley de Libertad Religiosa de 1980) y los acuerdos con las confesiones no católicas de 1992. Actualmente, se conocen iniciativas parlamentarias y un proyecto gubernamental de revisar la Ley de Libertad Religiosa. Se producen como respuesta al pluralismo religioso, producido principalmente por el notable aumento de la población inmigrante.

En las últimas décadas se puede apreciar que la labor del franquismo no logró hacer desaparecer los cambios de mentalidad anteriores (aunque sí los invisibilizó), ni impedir la influencia exterior del turismo y las industrias culturales en la apertura de los años 50. Por ello, tras la desaparición del dictador, eclosiona de nuevo con fuerza en España un impulso secularizador que se ha mantenido en una tendencia creciente 2 .

\footnotetext{
${ }^{2}$ La rapidez con que ha tenido lugar esta secularización y el modo en que alcanza a las generaciones socializadas en el nacionalcatolicismo, sugieren que en la magnitud de la socialización franquista era mucho menor de lo que parecía, y bastante mayor el camuflaje que empleaba la sociedad. Lo socialmente deseable, aquello que en público debía reconocerse como correcto y que actuaba como control social ideológico, es lo que realmente se ha disuelto más rápidamente. El deseable social, mucho menos anclado en las creencias personales de lo que en ocasiones se cree, es bastante más volátil y sensible para reaccionar ante el cambio social. Como indica Comas (2004:322), refiriéndose a la ausencia de una "narrativa" común en la sociología española respecto a este periodo: "algunos argumentos consideran que el dominio nacional-católico reestableció, en los términos previstos por el absolutismo, la vieja sociedad católica del antiguo régimen, mientras
} 
La secularización (situación en la cual la religión no juega un papel estructural determinante en la sociedad) de la vida política y social en España es un hecho. Como se puede observar en la evolución de las creencias religiosas de los españoles, el porcentaje que se manifiesta "católico practicante" ha disminuido sustancialmente en cincuenta años; pasando de un porcentaje superior al $80 \%$ en los años 60 al $25 \%$ en 2005. También se observa un incremento de aquellos que se consideran católicos no practicantes (aproximadamente el 55\%).

\section{Gráfico 1.}

Evolución de las creencias religiosas de los españoles (1965-2005) \%.

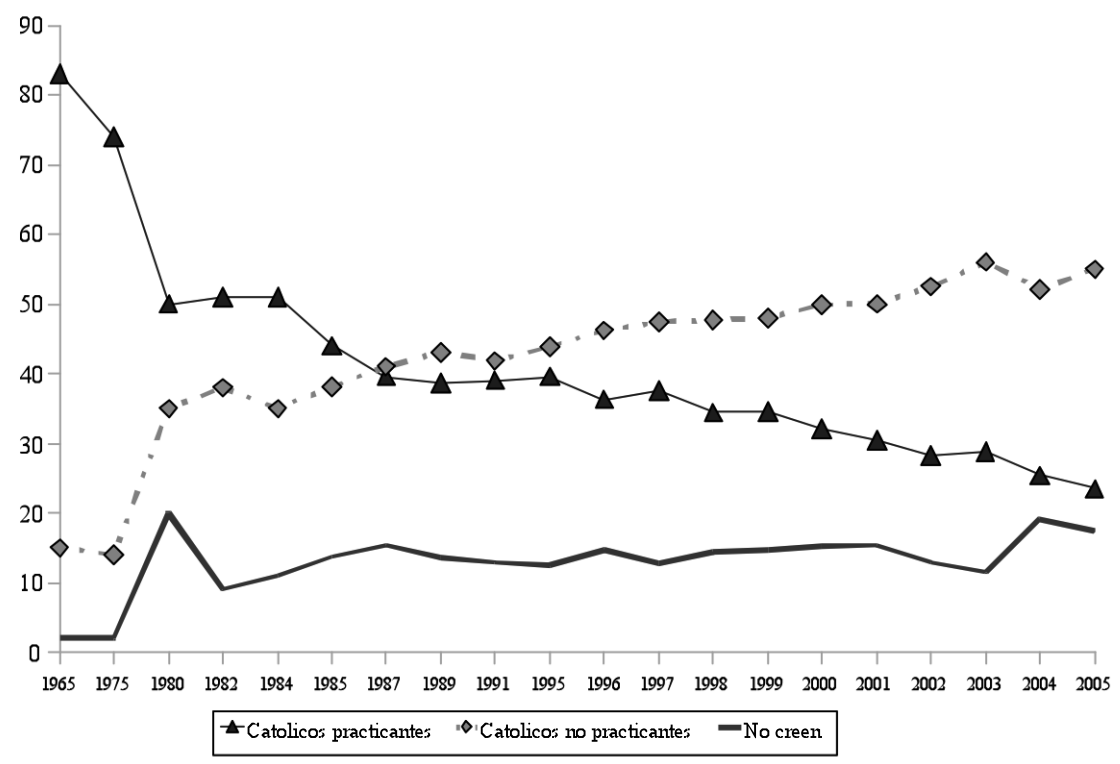

Fuente: Alaminos y Penalva (2008) a partir de los datos de Díaz Salazar (1993) y Tezanos (2006).

que otros argumentos interpretan que esto es cierto en lo formal pero no en el ámbito de las conciencias individuales". No obstante, la hipótesis de lo que podríamos llamar "invisibilización" del cambio cultural anterior a la Guerra Civil por parte del franquismo y la persistencia de la secularización en el ámbito privado durante el régimen, es difícil de probar por la ausencia de datos y la ambigüedad de los indicadores incluidos en las escasas encuestas realizadas en ese periodo. 
La noción de "católico no practicante" resulta de la síntesis entre los esfuerzos patrióticoidentitarios del nacionalcatolicismo y su fracaso como referente de los usos y normas sociales de los españoles. Definirse como católico no practicante indica, precisamente, que los contenidos y prescripciones de la jerarquía católica, así como su intento de influir en la política, están en contradicción con los procesos de modernización política y de liberalización de las costumbres que se observan en la sociedad española actual. Existen multitud de aspectos de la vida social en los que la jerarquía católica se sitúa claramente fuera de la modernidad (la reprobación de prácticas relativas a la contracepción, la unión libre de parejas, o la libertad sexual). Es por ello que la identificación mayoritaria como católico se debe interpretar exclusivamente como identitaria entre los no practicantes. Identitaria en el sentido de establecer un carácter distintivo frente a otras religiones, culturas o naciones.

\section{GLOBALIZACIÓN Y PLURALISMO RELIGIOSO}

Para algunos autores se ha producido una transformación de las prácticas y del contenido de las creencias, sin suponer por ello su desaparición. Aunque en cualquier caso la influencia de la jerarquía eclesiástica en las sociedades europeas es mínima, estos autores destacan que la secularización no conduce a la desaparición de la religión en la sociedades modernas, sino más bien a una recomposición de las creencias y expresiones religiosas (Hervieu-Léger et al. 1992; Davie y Hervieu-Léger 1996 y Casanova 2006) en un contexto de competencia religiosa producto del fenómeno de globalización. Elzo (2008b) también alude a una reconstrucción de lo religioso en términos de elaboración de un universo confesional caracterizado por el bricolaje, el sincretismo, la búsqueda de identidad emocional y como sustrato de identificación religiosa en algunos movimientos políticos. La religión se vuelve subjetiva y privada, apartada de las instituciones confesionales oficiales, de tal manera que se hace "invisible" (Luckmann 1973; 1989). Esta privatización se produce como consecuencia del proceso de diferenciación de las sociedades, en las cuales lo sagrado pasa de impregnar todas las esferas de la vida social a mantenerse a partir de instituciones específicas. La consecuencia es el surgimiento de un modelo oficial de interpretación de lo sobrenatural y de producción de prescripciones que pueden tropezar con la religiosidad individual. A esto se añade la competencia de diferentes religiones que coexisten en un contexto pluralista, y la rigidez y lentitud de las iglesias a la hora de adaptarse a los cambios producidos en los otros ámbitos. Todo ello concuerda con la dimensión religiosa del proceso de individuación que señala Beck (2009) en El Dios personal. La individuación se entiende en un contexto en el que el individuo no encuentra sistemas regularizados y estables sobre los cuales conseguir seguridad y fuentes de identidad. Los individuos han de diseñar sus propias biografías, relaciones sociales y creencias. Esta autonomización de la conciencia, sin imposiciones institucionales provenientes de la Iglesia, estaría 
asociada a la recomposición de lo religioso y es coherente con el resto de ámbitos donde el individuo deja de tener referentes identitarios claros en el proceso de socialización (trabajo, escuela, familia). Por otro lado, en términos societales, Berger (2008) señala que verdaderamente la relación no es tanto entre modernización y secularización, como entre modernización y pluralismo. A excepción de lo que ocurre en Europa Occidental y Central donde la decadencia de la religión es un rasgo de su identidad cultural, Berger alude a los resurgimientos de lo religioso en el resto del mundo.

Los procesos migratorios pueden suponer un incremento de la heterogeneidad axiológica de los países receptores. Las sociedades multiculturales muestran como rasgo característico un mosaico de axiologías segmentadas, de origen tanto étnico como religioso. En medio de este pluralismo, aparece la necesidad de buscar unos espacios comunes de acuerdo moral. Esa necesidad de consenso también aparece en el ámbito de las religiones. El Parlamento de las Religiones Mundiales firmó en 1993 una Declaración en pro de una Ética Mundial en la cual se afirmaba que "[...] es absolutamente necesario comprometerse por los derechos humanos, la libertad, la justicia, la paz y la conservación de la Tierra; que las distintas tradiciones religiosas y culturales no deben ser un obstáculo para que todos juntos trabajemos activamente a favor de una mayor humanización de la vida y en contra de todo tipo de discriminación y actividad que deshumanice la vida; que los principios en los que se sustenta la declaración puedan ser compartidos por todos, y para ello pretende recoger aquellos principios y valores éticos comunes que están presentes en las grandes tradiciones religiosas." Una declaración semejante aparece en el Informe de la Comisión Mundial sobre la Cultura y el Desarrollo Nuestra diversidad creativa (United Nations Educational, Scientific and Cultural Organization 1996:32).

Para clarificar en qué condiciones se encuentran la ética religiosa y la ética civil para alcanzar un consenso mínimo intercultural, es preciso considerar dos conceptos clave que las describen, atendiendo al ámbito de regulación vital de los individuos: las "éticas de máximos" y las "éticas de mínimos".

Las "éticas de máximos", pertenece a las éticas de las tradiciones religiosas que están orientadas a la búsqueda de la felicidad y del sentido de la vida y, por ello, proponen a sus adherentes ideales de vida que no se pueden imponer a quienes no comparten su credo. Contienen principios orientados a una vida digna de ser vivida, acogidos en visiones del mundo que pueden ser de origen tanto laico como religioso: "Las éticas de la felicidad [...] intentan ofrecer ideales de vida buena, en los que el conjunto de bienes de que los hombres podemos gozar se presentan jerarquizadamente como para producir la mayor felicidad posible. Son, por tanto, éticas de máximos que aconsejan seguir su modelo, nos invitan a tomarlo como orientación de la conducta, pero no pueden exigir que se sigan, porque la felicidad es cosa de consejo e invitación, no de exigencia" (Cortina y Martínez 1998:117-118).

En contraste, las "éticas de mínimos" proponen una serie limitada de principios que favorecen la convivencia entre credos y maneras de vivir. Las éticas de mínimos se ocupan de aquellos deberes que son exigibles a cualquier ser racional y que, en 
definitiva, sólo componen unas exigencias mínimas para lograr una convivencia pacífica entre los ciudadanos. Sintéticamente, podríamos decir que la ética de mínimos consta de tres elementos básicos: a) un conjunto limitado de valores y normas; b) son producto de la racionalidad y, c) se basan en el consenso. Las éticas de mínimos son denominadas "éticas de la justicia" (al componerse de derechos y deberes morales y jurídicos) y también "ética civil". Ciertamente, es una propuesta ética para sociedades que aceptan los principios emanados de la Revolución Francesa. En un entorno plural respecto a los modos de vida y las creencias, se hace necesario un conjunto moral mínimo que salvaguarde el pluralismo de proyectos humanos y la aconfesionalidad; y que se ocupe únicamente de la dimensión universalizable del fenómeno moral. La ética civil se agota pronto en cuanto a dimensiones de la vida pero tiene un gran alcance por su carácter universal en cuanto a deberes y derechos; no solo los derechos civiles y políticos, sino también los sociales, en su faceta de justicia social.

La ética civil es capaz de responder a los desafíos de la multiculturalidad. Su realización social es un producto histórico condicionado por los procesos que viven las sociedades. En ese sentido, "la ética civil, en cuanto conjunto de valores y orientaciones morales compartidas en un momento histórico social, tiene el carácter de un cierto precipitado moral: un proceso de decantación efectuado a través de vicisitudes y confrontaciones sociales" (Mardones 1995). Así, Rawls (1971) ve en la ética civil un solapamiento de valores y normas morales que proceden de la vida social misma, con sus complejidades, desacuerdos y negociaciones. En ese sentido, la ética civil busca y produce un "consenso solapante". El grado en que las éticas de máximos pueden llegar a ser compatibles 0 excluyentes entre sí y con respecto a las éticas de mínimos es una cuestión de contexto social. Allí donde religión y Estado se integran, las posibilidades de exclusión y conflicto son mayores.

\section{MÉTOdo}

Según los antecedentes expuestos se pueden considerar dos fuentes de los principios que rigen el comportamiento moral. Por un lado la religión y por otra, en contraposición con la primera, la razón y los derechos humanos. La ética religiosa tiene un elemento trascendental del que carece la ética civil: es un ser superior el que dota de sentido moral la mayoría de las acciones y propuestas del creyente. En ese sentido, la creencia en Dios como fundante de los valores es un indicador clave: " $¿ E s$ preciso creer en Dios para tener un comportamiento moral?" Las respuestas afirmativas o negativas son las que permite diferenciar claramente los referentes de la ética religiosa y la civil. En ese sentido, la variable que expresa y articula las diferencias entre una ética civil y religiosa viene indicada por la necesidad de creencia en Dios para poder ser moral. Una, anclada en la necesidad de Dios como fuente de la moralidad y el respeto a lo que es justo; y otra, donde la moral, el respeto a los demás y el comportamiento cívico no lo necesitan. 
Las hipótesis que se plantean en este estudio, formuladas en forma de preguntas de investigación, serían las siguientes:

H1. ¿Existe y qué importancia tiene socialmente la ética civil en España? Es decir, un comportamiento moral sin Dios.

H2. En el caso de que exista y sea socialmente relevante ¿existen variables estructurales como son educación, edad, género, ubicación ideológica que expliquen las diferencias entre que los ejercen una u otra ética?

H3. Actuando como control de validez de la diferenciación entre éticas que mide la operacionalización: ¿Existe una relación entre las éticas adoptadas y el indicador de religiosidad que expresa la importancia de la religión en su vida?

H4. ¿Cuáles son las consecuencias en términos de opinión y comportamiento? ¿se producen de forma significativa formas diferentes de opinar sobre el mundo según la orientación ética? Esta posibilidad conduce al testado de varias subhipótesis:

H4.1. ¿Existe una relación entre la ética adoptada y la creencia en el control que los individuos tienen sobre su vida? Es decir, en la creencia en el libre albedrío o la divina providencia.

H4.2. ¿Existe una relación entre la ética adoptada y la valoración de la intervención de los líderes religiosos en la sociedad?

H4.3. ¿Existe una relación entre la ética adoptada y la percepción de modernización de la sociedad española?

H4.4. ¿Existe una relación entre la ética adoptada y la influencia de la religión en el Estado?

H5. ¿Existe una estructura estadística y teóricamente significativa que integre de forma lógicamente consistente las opiniones y comportamientos observados?

Con la finalidad de responder a las hipótesis se han realizado dos operaciones complementarias a partir de la utilización de dos técnicas de análisis: 1) Un análisis de frecuencias de las preguntas más relevantes de la encuesta internacional Pew Global Attitudes Project efectuada en la primavera de 2007, que nos permiten obtener una visión global de los contenidos de la ética civil a partir de los resultados obtenidos de los principales indicadores recogidos en la encuesta estudiados separadamente; y 2) la elaboración de un modelo estructural que se basa en estos mismos indicadores, del cual se obtiene una visión del conjunto, y que da respuesta a las hipótesis que apuntan hacia la determinación del peso de los factores estructurales en la conformación de la ética civil, así como su influencia en cuanto a actitudes y comportamientos respecto a aspectos existenciales, la práctica religiosa y el peso de la religión en la vida pública.

La muestra de la encuesta para España $(n=500)$ es de representación nacional, con un error de $+/-4,4 \%$ para un p/q $=50 / 50$ en intervalo de confianza del $95,5 \%$ (2 sigmas). El trabajo de campo fue efectuado mediante entrevistas personales en rutas aleatorias. Las preguntas en esta encuesta miden los conceptos teóricos contemplados 
en las hipótesis evaluadas. La pregunta sobre la necesidad de creer en Dios para poseer valores morales y ser honesto, indica de modo simplificado las fuentes alternativas de la moral: una fundamentada en las creencias religiosas (Dios) frente a las posibles alternativas de valores morales cívicos (sin Dios). Esta separación analítica de la moral respecto a las fuentes que la validan ofrece la posibilidad de estudiar la coexistencia de una moralidad religiosa junto a otra cívica.

\section{Resultados}

\section{Ética civil en España: indicadores}

Respecto a la primera hipótesis, sobre si existe y qué importancia tiene socialmente la ética civil en España, la respuesta es afirmativa. El $70 \%$ de la población indica que no hace falta creer en Dios para tener moral y poseer valores morales. Un $25 \%$ sí considera necesario ser creyente. Se puede observar que la pregunta está realizada de manera impersonal, no se pregunta si se es o no creyente, sino si creer es condición necesaria para tener un comportamiento ajustado a valores justos de convivencia. En principio, tanto un creyente como un no creyente pueden contestar afirmativa o negativamente. La secularización como proceso produce este resultado: la presencia de otros referentes ético-morales basados en principios no confesionales. Nótese (tabla 1) la posición que ocupa España (séptima) en esta distribución de frecuencias en orden descendente. Una posición muy cercana a la de otros países del entorno muy secularizados, de una composición étnica más diversa y antigua (países colonizadores hasta mitad del siglo $X X$ ), de mayor experiencia en cuanto a cultura democrática (asociado a la tolerancia, el desarrollo de los derechos civiles y la secularización casi total de la política) y de países ex comunistas. 
Tabla 1.

Las fuentes de los valores.

\begin{tabular}{|c|c|c|c|c|c|}
\hline & $\begin{array}{l}\text { No es preciso creer en } \\
\text { Dios para tener valores y } \\
\text { ser una persona moral }\end{array}$ & $\begin{array}{c}\text { Es preciso creer en } \\
\text { Dios para tener valores y } \\
\text { ser una persona moral }\end{array}$ & No sé & $\begin{array}{c}\text { No } \\
\text { contesta }\end{array}$ & Total \\
\hline Suecia & $86,00 \%$ & $10,40 \%$ & $2,60 \%$ & $1,00 \%$ & $100 \%$ \\
\hline Republica Checa & $85,10 \%$ & $13,80 \%$ & & $1,10 \%$ & $100 \%$ \\
\hline Francia & $83,50 \%$ & $16,50 \%$ & & & $100 \%$ \\
\hline Gran Bretaña & $75,10 \%$ & $21,90 \%$ & $2,80 \%$ & $0,20 \%$ & $100 \%$ \\
\hline China & $72,30 \%$ & $17,50 \%$ & $9,60 \%$ & $0,60 \%$ & $100 \%$ \\
\hline Italia & $70,90 \%$ & $24,00 \%$ & $3,80 \%$ & $1,40 \%$ & $100 \%$ \\
\hline España & $70,80 \%$ & $25,20 \%$ & $2,60 \%$ & $1,40 \%$ & $100 \%$ \\
\hline Polonia & $68,70 \%$ & $29,40 \%$ & $1,20 \%$ & $0,80 \%$ & $100 \%$ \\
\hline Rusia & $67,70 \%$ & $25,90 \%$ & $5,80 \%$ & $0,60 \%$ & $100 \%$ \\
\hline Bulgaria & $67,60 \%$ & $24,40 \%$ & $7,80 \%$ & $0,20 \%$ & $100 \%$ \\
\hline Canadá & $67,10 \%$ & $30,30 \%$ & $1,60 \%$ & $1,00 \%$ & $100 \%$ \\
\hline Eslovaquia & $63,60 \%$ & $34,20 \%$ & $1,60 \%$ & $0,70 \%$ & $100 \%$ \\
\hline Alemania & $59,60 \%$ & $38,60 \%$ & $1,20 \%$ & $0,60 \%$ & $100 \%$ \\
\hline Israel & $54,80 \%$ & $42,60 \%$ & $2,20 \%$ & $0,40 \%$ & $100 \%$ \\
\hline Japón & $53,40 \%$ & $32,70 \%$ & $13,60 \%$ & $0,30 \%$ & $100 \%$ \\
\hline Argentina & $51,80 \%$ & $45,20 \%$ & $2,60 \%$ & $0,40 \%$ & $100 \%$ \\
\hline Ucrania & $50,40 \%$ & $42,40 \%$ & $6,00 \%$ & $1,20 \%$ & $100 \%$ \\
\hline Chile & $47,60 \%$ & $50,60 \%$ & $1,00 \%$ & $0,80 \%$ & $100 \%$ \\
\hline México & $44,20 \%$ & $53,00 \%$ & $2,30 \%$ & $0,50 \%$ & $100 \%$ \\
\hline Estados Unidos & $41,20 \%$ & $57,30 \%$ & $0,70 \%$ & $0,90 \%$ & $100 \%$ \\
\hline Corea del Sur & $36,80 \%$ & $55,60 \%$ & $6,50 \%$ & $1,10 \%$ & $100 \%$ \\
\hline Líbano & $33,30 \%$ & $65,60 \%$ & $1,10 \%$ & $0,00 \%$ & $100 \%$ \\
\hline India & $32,60 \%$ & $65,70 \%$ & $1,50 \%$ & $0,20 \%$ & $100 \%$ \\
\hline Perú & $29,00 \%$ & $69,90 \%$ & $1,00 \%$ & $0,10 \%$ & $100 \%$ \\
\hline Bolivia & $27,30 \%$ & $70,10 \%$ & $2,30 \%$ & $0,20 \%$ & $100 \%$ \\
\hline Venezuela & $26,80 \%$ & $72,60 \%$ & $0,50 \%$ & $0,10 \%$ & $100 \%$ \\
\hline Ghana & $23,90 \%$ & $73,00 \%$ & $1,60 \%$ & $1,60 \%$ & $100 \%$ \\
\hline Suráfrica & $23,90 \%$ & $74,10 \%$ & $1,40 \%$ & $0,60 \%$ & $100 \%$ \\
\hline Etiopía & $22,70 \%$ & $76,30 \%$ & $0,10 \%$ & $0,80 \%$ & $100 \%$ \\
\hline Costa de Marfil & $22,30 \%$ & $77,70 \%$ & & & $100 \%$ \\
\hline Malí & $18,40 \%$ & $81,30 \%$ & $0,30 \%$ & & $100 \%$ \\
\hline Kenia & $18,30 \%$ & $80,90 \%$ & $0,60 \%$ & $0,20 \%$ & $100 \%$ \\
\hline Nigeria & $17,90 \%$ & $81,80 \%$ & $0,40 \%$ & & $100 \%$ \\
\hline Brasil & $16,50 \%$ & $83,30 \%$ & $0,20 \%$ & & $100 \%$ \\
\hline Uganda & $12,60 \%$ & $86,60 \%$ & $0,80 \%$ & & $100 \%$ \\
\hline Kuwait & $12,20 \%$ & $87,00 \%$ & $0,20 \%$ & $0,60 \%$ & $100 \%$ \\
\hline Malasia & $12,10 \%$ & $85,60 \%$ & $1,90 \%$ & $0,40 \%$ & $100 \%$ \\
\hline Turquía & $11,70 \%$ & $84,10 \%$ & $3,30 \%$ & $0,80 \%$ & $100 \%$ \\
\hline Tanzania & $10,80 \%$ & $89,20 \%$ & & & $100 \%$ \\
\hline Senegal & $9,30 \%$ & $90,70 \%$ & & & $100 \%$ \\
\hline Palestina & $8,80 \%$ & $84,00 \%$ & $5,10 \%$ & $2,10 \%$ & $100 \%$ \\
\hline Pakistán & $8,50 \%$ & $88,10 \%$ & $3,40 \%$ & $0,00 \%$ & $100 \%$ \\
\hline Bangladesh & $6,30 \%$ & $89,80 \%$ & $3,90 \%$ & & $100 \%$ \\
\hline Indonesia & $1,40 \%$ & $98,50 \%$ & $0,10 \%$ & & $100 \%$ \\
\hline Jordania & $0,10 \%$ & $96,90 \%$ & $1,30 \%$ & $1,70 \%$ & $100 \%$ \\
\hline Egipto & & $99,00 \%$ & $0,40 \%$ & $0,60 \%$ & $100 \%$ \\
\hline Total & $34,70 \%$ & $62,10 \%$ & $2,70 \%$ & $0,50 \%$ & $100 \%$ \\
\hline
\end{tabular}

Fuente: Elaboración propia sobre microdatos, encuesta Pew Global Attitudes Project 2007. 
A continuación presentamos las distribuciones de frecuencia dicotomizadas (fundiendo algunas categorías que apuntan hacia la intensidad de la actitud y excluyendo las "no respuesta" y las "no sabe"): desde aspectos relacionados con la práctica cotidiana de la religión, con preguntas de hecho (frecuencia de rezo) o de opinión que vinculan el papel sociopolítico de la religión (separación religión-Estado; influencia de los líderes religiosos) hasta aspectos existenciales más subjetivos (destino o autonomía individual), de guía vital (importancia de la religión en la vida) o identitarios (modo tradicional de vida). Los resultados se exponen en dos columnas, agrupando en cada una de ellas las preguntas, por un lado, más próximas al proceso de secularización y, por otro, las que consideramos que están más relacionadas con el peso de lo sagrado.

Tabla 2.

Ética civil y religiosa en España.

\begin{tabular}{|c|c|c|}
\hline & $\begin{array}{l}\text { ÉTICA CIVIL } \\
\text { (Secular) }\end{array}$ & $\begin{array}{l}\text { ÉTICA RELIGIOSA } \\
\text { (Eclesial) }\end{array}$ \\
\hline $\begin{array}{l}\text { Es preciso creer en Dios para tener } \\
\text { valores y ser una persona moral }\end{array}$ & $\begin{array}{c}\text { No } \\
70,80 \%\end{array}$ & $\begin{array}{c}\text { Sí } \\
25,20 \%\end{array}$ \\
\hline $\begin{array}{l}\text { La influencia de los líderes } \\
\text { religiosos es muy buena, buena, } \\
\text { mala o muy mala para España }\end{array}$ & $\begin{array}{l}\text { Más bien mala o muy mala } \\
\qquad 54 \%\end{array}$ & $\begin{array}{l}\text { Muy buena o más bien buena } \\
\qquad 32,40 \%\end{array}$ \\
\hline Importancia de la religión en su vida & $\begin{array}{l}\text { Poca o ninguna importancia } \\
\qquad 55,00 \%\end{array}$ & $\begin{array}{c}\text { Muy o bastante importante } \\
\qquad 43,80 \%\end{array}$ \\
\hline Frecuencia con que reza & $\begin{array}{l}\text { Nunca } \\
50 \%\end{array}$ & $\begin{array}{c}\text { Todos los días + algunas } \\
\text { veces o menos } \\
46,6\end{array}$ \\
\hline $\begin{array}{l}\text { El éxito en la vida está determinado } \\
\text { por fuerzas fuera de nuestro control }\end{array}$ & $\begin{array}{c}\text { Bastante o completamente en } \\
\text { desacuerdo } \\
39,60 \%\end{array}$ & $\begin{array}{l}\text { Total o bastante de acuerdo } \\
\qquad 52,80 \%\end{array}$ \\
\hline $\begin{array}{l}\text { Nuestro modo tradicional de vida se } \\
\text { está perdiendo o permanece fuerte }\end{array}$ & $\begin{array}{l}\text { Se está perdiendo } \\
\qquad 79,00 \%\end{array}$ & $\begin{array}{l}\text { Permanece fuerte } \\
\qquad 16,80 \%\end{array}$ \\
\hline
\end{tabular}

Fuente: Elaboración propia sobre microdatos, encuesta Pew Global Attitudes Project. 


\section{El modelo estructural}

El modelo que especificamos testa las hipótesis propuestas, mediante el contraste empírico de las relaciones teóricas esperadas entre las variables citadas anteriormente. En este modelo, la ética cívica y religiosa se encuentra en la base de las opiniones referidas a la presencia y función de los valores religiosos y la intervención de la iglesia católica en la vida cotidiana ${ }^{3}$.

El modelo ajusta óptimamente. Con 23 grados de libertad y un valor de Chi cuadrado de 17,42, muestra un coeficiente $P$ de .78 y un RMSAinferior al .000. La bondad del ajuste del modelo es elevada. El sistema estructural del Cuadro 2 (ver Anexo Metodológico) muestra los coeficientes estandarizados y, bajo cada uno de ellos, el error y su valor $t$. Todos los coeficientes, como puede apreciarse, son significativamente diferentes de cero.

El modelo estructural especificado es consistente empíricamente con los datos. Consideradas las ecuaciones, podemos apreciar la varianza explicada de la variable dependiente mediante el coeficiente de determinación. Es importante advertir que el objetivo del contraste empírico es evaluar la consistencia entre el modelo estructural y los datos. Es decir, de las relaciones entre variables dentro de un modelo 0 argumentación. En ese sentido, las ecuaciones individuales no están especificadas para optimizar la varianza explicada en la dependiente. Sin duda, existen variables que pueden ayudar a incrementar la varianza explicada en cada ecuación. Sin embargo, la finalidad del modelo es evaluar la explicación en conjunto: en qué forma el sistema de opiniones y comportamientos especificado teóricamente encuentra apoyo en los datos (H5). En definitiva, en qué modo las posiciones éticas se asocian y explican las actitudes, opiniones y comportamientos considerados de la sociedad española. Una descripción general de resultados sobre la base de varianzas explicadas nos indica que la variable cuya varianza es explicada en mayor grado por las variables especificadas en el modelo es la de "frecuencia con que se reza" $\left(Y_{7}\right)$, con un coeficiente de determinación del .60. Es decir, un $60 \%$ de varianza explicada. Le sigue la variable que mide la "importancia que tiene la religión en su vida" $\left(\mathrm{Y}_{\mathrm{g}}\right)$ con un coeficiente de determinación del .22. Otra variable con un nivel de varianza explicada importante es la opinión sobre la "participación de los líderes religiosos en la vida política" $\left(\mathrm{Y}_{3}\right)$, con un coeficiente de determinación de .20. La opinión sobre los cambios y modernización que experimenta la sociedad española $\left(\mathrm{Y}_{6}\right)$ muestra un coeficiente de determinación del .16.

En general, las variables dependientes con una menor varianza explicada son aquellas con una relación indirecta con las creencias religiosas. Un caso especial es la autoubicación ideológica. Es evidente la limitación de explicar la autoubicación ideológica (Y1) mediante la variable género exclusivamente; de ahí el .024 del coeficiente de deter-

\footnotetext{
${ }^{3}$ Una información técnica más amplia sobre el modelo estructural realizado, que incluye la composición de las variables así como las fórmulas y coeficientes, se puede encontrar en el anexo metodológico ubicado al final del artículo.
} 


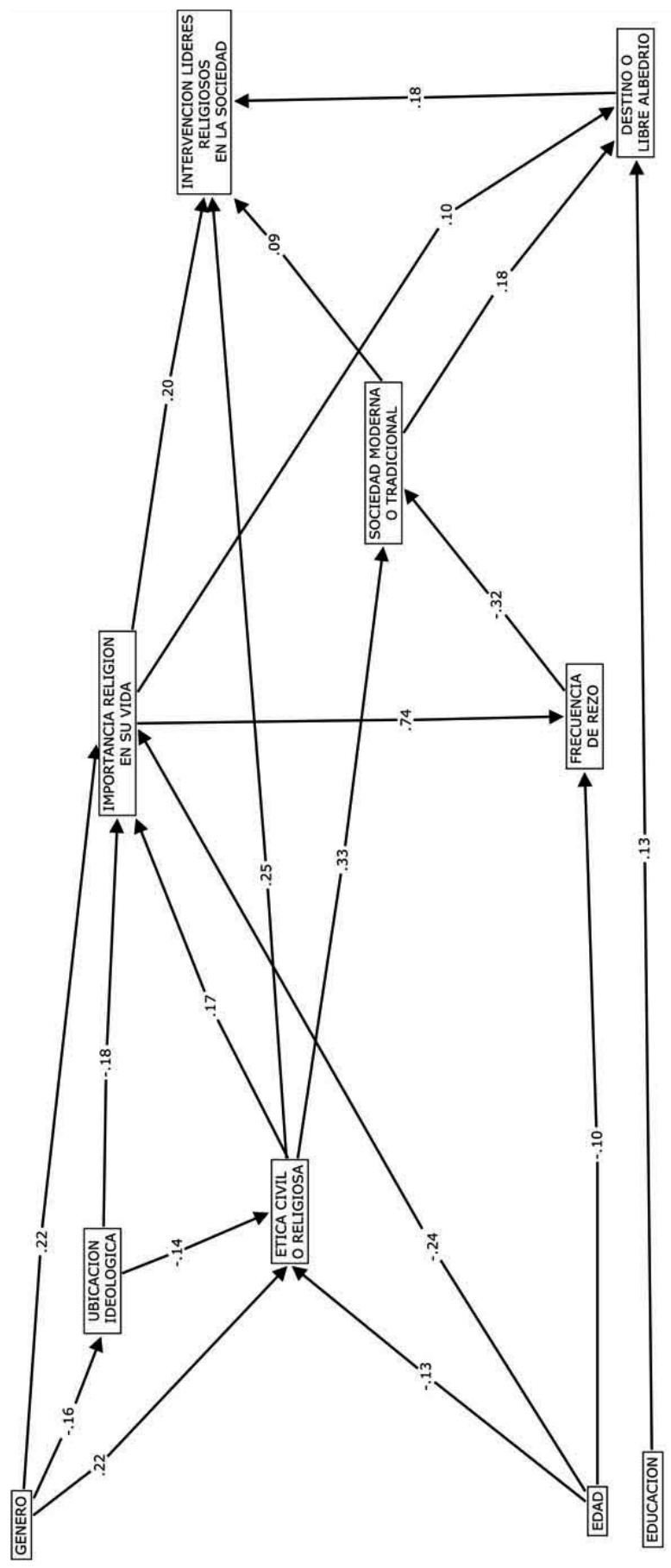


minación. En este caso, como ya se advirtió, la función en la especificación del efecto de género sobre ideología es de control estadístico más que de intento de explicación de la ideología. Algo semejante sucede con la variable que mide las diferencias entre ética cívica y ética religiosa (Y4). Su dependencia es directa de variables estructurales como género, edad y en cierto modo ideología. Estas variables aún cuando tienen un efecto estadísticamente significativo, muestran una capacidad explicativa final reducida. Género, edad o ideología explican un $9 \%$ de la opción entre éticas. Precisamente en esa opción entre éticas destaca su independencia empírica del nivel educativo. Como ya anticipábamos, los procesos de elección son merecedores por sí mismos de una investigación específica. En este caso, su finalidad teórica última es determinar su capacidad explicativa sobre las opiniones, creencias y comportamientos sociales. Las variables que miden la creencia del individuo en el libre albedrío (Y2), así como la opinión sobre la necesidad de separar religión y Estado (Y5) son explicadas en un 6\%.

Para considerar las diferentes hipótesis especificadas emplearemos la tabla 3, que resume de forma analítica las relaciones dentro del modelo estructural. Con respecto a la hipótesis 2, en relación al papel de las variables educación, edad, género o ideología que explican las diferencias entre los que ejercen una u otra ética; la influencia mayor se produce para la variable género (.22), donde en la ética civil los hombres tienen un mayor peso; mientras que las mujeres lo tienen en la ética religiosa. En ese sentido, la variable edad es también una influencia estadísticamente significativa (-.13): los jóvenes están más próximos a una ética sin necesidad de Dios. La tercera variable con capacidad explicativa es la autoubicación ideológica (-.14). Los individuos que se afirman más de izquierdas están identificados en mayor grado con una ética civil, mientras que los más a la derecha consideran imprescindible la creencia en Dios para poder tener un comportamiento moral. Una relación que los datos indican como no significativa (controlado por edad y género) es el nivel educativo. No puede afirmarse sobre la base de estos datos que la educación sea un factor relevante en la adopción de una ética u otra.

En conjunto, los datos son acordes con las relaciones esperadas, tanto en signo como en significatividad estadística. Así, las mujeres (.22) y los individuos de más edad $(-24)$ reconocen una mayor importancia de la religión en sus vidas. Además los individuos de mayor edad (-.10) expresan de forma estadísticamente significativa una mayor frecuencia de rezo, indistintamente del género. La edad funciona también como referente respecto al papel del Estado y la religión. Los más jóvenes muestran una mayor disposición a separar la fe del Estado (-.19). En general, la edad muestra un diferencial claro respecto a la religiosidad o expectativa de influencia de la religión en la sociedad civil. La educación, medida como años cursados de educación, tiene empíricamente un comportamiento acorde con la expectativa teórica, donde los individuos más educados aceptan la conveniencia de separar la fe personal del Estado (.13), así como el libre albedrío por encima del designio divino (.13).

El posicionamiento ideológico muestra la relación esperada, donde la autoubicación en la izquierda ideológica se asocia con una menor importancia concedida a la religión. En ese sentido, la mayor significatividad de la religión en las vidas de los individuos de 
derechas es empíricamente contrastable (-.18). En conjunto, las variables estructurales expresan un panorama de cambio social donde la secularización de la sociedad se aprecia a través de los efectos de la edad.

En conjunto, las variables edad y género son especialmente significativas considerando sus efectos directos sobre la estructura de opiniones, creencias y comportamientos considerados. No obstante, la evaluación de los efectos directos nos ofrece una visión parcial de la influencia de estas variables. La consideración de los efectos totales permite determinar la influencia final que ejercen, en ocasiones a través de efectos indirectos mediante otras variables. La tabla 4 muestra los efectos totales de las variables edad, género y educación e ideología. La influencia total de género o edad sobre la adopción de una ética civil o religiosa está infraestimada, dado que la secuencia de signos no es consistente. Los efectos totales se ofrecen expresados en coeficientes estandarizados.

El efecto total del género es especialmente importante en la opción entre ética civil o religiosa (.24), defender la participación pública de los líderes religiosos (.12), una mayor importancia de la religión en sus vidas (.29), o una mayor frecuencia de rezo (.22). Una visión de conjunto permite apreciar una mayor participación de la mujer en las estructuras de opinión favorables a la religión. Tal y como observábamos en los efectos directos, la edad es indicadora clara del cambio social (aun cuando éste aparezca más atenuado interaccionando según género). Los más jóvenes, en relación a los mayores, son más partidarios de la separación entre religión y Estado (.14), muestran una mayor representación de una ética civil (-.13), una menor importancia de la religión en sus vidas $(-.26)$ y una menor frecuencia de rezo (-.30). Finalmente, la educación en sus efectos totales, es significativamente importante para reconocer la diferenciación entre Estado y religión y el predomino del libre albedrío de los individuos sobre aquellos que aceptan los designios divinos (.13). Como comentábamos, la educación no es enemiga de la fe o la religión, pero sí es opuesta, como cambio medio esperado, a las interferencias entre los valores religiosos y Estado, o la imposición de la doctrina de la jerarquía católica (en definitiva, intérpretes de la voluntad divina). Los coeficientes de bondad de ajuste, la edad y el género son variables significativas para explicar las diferencias en la aceptación de una ética civil respecto a otra religiosa. No es el caso del nivel educativo.

Con respecto a la hipótesis 3 , que funciona como control de validez de los contenidos atribuidos a las diferentes éticas consideradas, y que evalúa la relación entre las éticas adoptadas y el indicador de religiosidad que expresa la importancia de la religión en su vida, cabe afirmar que esta relación sí existe y que es significativa. Un coeficiente de .17, estadísticamente significativo, expresa la asociación entre la ética religiosa y una mayor importancia de la religión en su vida y viceversa: los individuos que expresan su creencia en la posibilidad de una ética cívica muestran una probabilidad menor de dar importancia a la religión en sus vidas cotidianas. En ese sentido, la opción ética comporta una mayor o menor relevancia a la dimensión religiosa.

Sobre las consecuencias de la opción ética sobre opiniones y comportamientos (hipótesis 4) debe observarse que la influencia se establece tanto de modo directo, como indirecto (mediante la intervención de otras variables). Así, consideremos las diferentes 
subhipótesis relacionadas para poder ilustrar lo dicho. De este modo, lo planteado en la subhipótesis 4.1. ¿Existe una relación entre la ética adoptada y la creencia en el control que los individuos tienen sobre su vida? La respuesta es que sí, pero de forma indirecta, mediante la intervención de otras variables. Estas son la importancia de la religión en su vida o la percepción de modernización en la sociedad. Es decir, en la medida en que estas dos variables vienen explicadas por la posición ética, Esta actúa indirectamente sobre la creencia en el libre albedrío o la divina providencia.

Sí existe un efecto directo claro entre las opciones éticas y la valoración de la intervención de los líderes religiosos en la sociedad (subhipótesis H 4.2). Con un coeficiente estandarizado de .25, los individuos que mantienen la necesidad de creer en Dios para poder tener un comportamiento moral y justo con los demás opinan que la intervención de los líderes religiosos es positiva para la sociedad. Por el contrario, los partidarios de una ética cívica opinan que las intervenciones de los líderes religiosos son negativas y que perjudican la convivencia entre los ciudadanos.

Asimismo, en relación a la subhipótesis 4.3. también existe un efecto directo de .33 entre el tipo de ética y la percepción de modernización de la sociedad. Los que creen viable la práctica de una ética civil perciben la sociedad española más modernizada y menos tradicional que los que apoyan una ética religiosa. En ese sentido, la opción ética parece condicionar la visión de la España en la que se vive.

Un efecto directo estadísticamente significativo (.14) se establece entre opción ética y la valoración de la influencia de la religión en el Estado. Los individuos que adoptan una ética civil opinan que la religión no debería intervenir en la política. Por el contario, los defensores de una ética religiosa (y acorde con lo que se afirmaba respecto a las éticas de máximos) opinan que la religión sí debe intervenir en la política. Como ya sabemos, la ética religiosa implica prescripciones y proscripciones de comportamiento que conducen a un buen vivir. Su aspiración de totalidad, y dada la experiencia histórica en España del catolicismo como religión oficial, explican esa preferencia intervencionista en el Estado de aquellos que mantienen una ética religiosa. La distinción entre religión y Estado es más evidente en el caso de los que mantienen la viabilidad de una ética civil. Por último, para la hipótesis 5, se aprecia que sí existe una estructura estadística y teóricamente significativa que integra de forma consistente las opiniones y comportamientos observados. Considerando los efectos directos, la adopción de una ética civil o religiosa tiene consecuencias evidentes en las opiniones y actitudes que expresan los individuos. Así, en términos directos, la adopción de una ética civil explica el rechazo a la intervención de los líderes religiosos en la vida social y política (.25), apoya la separación entre la fe personal y el Estado (.14), minimiza la importancia de la religión en sus vidas (.17), y piensa que la sociedad española se está modernizando y perdiendo los rasgos tradicionales (.33). La percepción de España como una sociedad moderna es característica de los que mantienen una ética civil frente a la religiosa.

Un aspecto central, con relevantes consecuencias sociales, es la importancia que los individuos dan al fenómeno religioso en su vida cotidiana. Así, aquellos que consideran que la religión es importante en su vida apoyan la intervención de los líderes católicos 
(.20), consideran la importancia de los designios de Dios (.10), ven la necesidad de que la fe esté presente en la vida social (.15), y tienen una elevada frecuencia de rezo (.74). Y todo lo contrario para aquellos que no conceden importancia a la religión en su vida. Con respecto a la percepción sobre si el modo tradicional de vivir se está perdiendo o permanece fuerte, los que opinan que se está perdiendo son partidarios de que los líderes religiosos no intervengan en la vida social (.90), y creen en la importancia del libre albedrío (.18) en los actos humanos y sus consecuencias. La percepción de la sociedad en la que se vive (dinámica y cambiante, o estática y tradicional), influye en el rol que se concede a las instituciones y actores sociales. Lógicamente, aquellos que consideran que el designio divino juega un papel en la vida de los seres humanos son favorables a la intervención de los líderes religiosos (al fin y al cabo, considerados sus intérpretes y portavoces) (.18). Asimismo, la frecuencia de rezo se asocia a una percepción de una sociedad tradicional aún fuerte (-.32).

Como puede apreciarse en conjunto, la estructura de valores, opiniones, actitudes y comportamientos son coherentes con la posición que se adopta respecto a la importancia de los valores cívicos o religiosos.

\section{DISCUSIÓN Y CONCLUSIONES}

Alo largo de la exposición de este artículo se ha comprobado la existencia de una ética civil bastante consistente y extendida en la sociedad española, que contrasta con la imagen tradicional de un país católico donde la religión ha tenido un papel histórico relevante en términos de influencia en la vida social y política. Los resultados son coherentes con las investigaciones previas sobre el proceso de secularización en este país, del que se ha dado cuenta en la introducción teórica y que apuntan a la consideración de España como uno de los países más secularizados del mundo. Del conjunto de indicadores (entre 1975 y 2005) sobre "religión y religiosidad" que Del Campo y Tezanos (2008:922-923) consideran, casi todos muestran una tendencia claramente negativa (creencia en el demonio, el pecado, Dios, la vida después de la muerte, cielo e infierno, alma y reencarnación) y los dos únicos que marcan una evolución creciente son los que miden el porcentaje de los "no creyentes, indiferentes y ateos" y "creyentes de otra religión". Precisamente, Elzo (2008b:463) estima que cerca de tres millones de personas en España (7\%) profesan una religión no católica (básicamente cristianos protestantes y ortodoxos; y musulmanes) y este dato es muy importante para completar el cuadro referido a la religiosidad y la secularización en España.

De hecho, en un contexto globalizado y de intensificación de los procesos migratorios, donde la convivencia es uno de los principales retos que se presentan, el conjunto mínimo de principios producto de la racionalidad y del consenso presenta una ventaja desde el punto de vista de su funcionalidad para asegurar la convivencia de grupos con diferentes raíces culturales y creencias; y por su adaptabilidad al cambio cultural y social. Es por ello que la virtud de la extensión de esta ética civil no es evaluar 
el triunfo de lo secularizado o lo laico sobre la religión; sino más bien su capacidad de incluir, a través del principio de tolerancia, tanto lo religioso en sus diferentes fuentes doctrinales y recomposiciones contemporáneas, como las concepciones no creyentes del mundo. Atenuando así los previsibles conflictos entre diferentes maneras de vivir y entre religiones que tradicionalmente se han excluido mutuamente.

Los resultados del presente estudio tienen consonancia con estudios recientes que muestran la sociedad española como una sociedad abierta, tolerante y moderna en la cual los valores más extendidos apuntan hacia los elementos que forman la ética civil. La mayoría de los españoles no solo presentan opiniones y conductas que apuntan positivamente hacia estos elementos, tal como se ha presentado al inicio de la exposición de los resultados de este estudio, sino que también perciben el país en el que viven como una sociedad cada vez más tolerante, menos conservadora y menos religiosa (Camacho 2008:840).

La exposición de un modelo estructural ha permitido observar los factores estructurales que influyen en la adopción de esta ética civil, cuyos resultados son coherentes con los estudios anteriores, en el sentido de observar una mayor predisposición a la misma por parte de los hombres, los más jóvenes y las personas autoubicadas ideológicamente en la izquierda. Estas tres variables son las que se citan en los estudios sobre secularización. En el caso de los jóvenes, en los estudios de González-Anleo (2006) se muestra claramente el desapego de éstos hacia la religión y la Iglesia. En otros, se emplean indicadores asimilables a los que se utilizan en el presente trabajo, como que la evaluación de valores liberales ("las personas tienen libertad y control sobre cómo les va la vida") por parte de los jóvenes contrasta con valores finalistas, más presentes en las personas mayores ("llevar una vida moral y digna") (Megías 2000). En un estudio comparado realizado por Elzo (2009) sobre datos de diferentes fuentes como la Encuesta Europea de Valores o el Eurobarómetro en los años 2000 y 2001, los jóvenes otorgaban una importancia de la religión en sus vidas semejante al de otras naciones europeas muy secularizadas como Francia, Dinamarca o Reino Unido, y muy distante con respecto a países mediterráneos: católicos (Italia), o con similar estado de modernización (Grecia). Además, los jóvenes mostraban puntuaciones favorables más altas que la media europea (e incluso en algunos asuntos la más alta) en torno a cuestiones en los que la Iglesia se ha opuesto frontalmente, como la eutanasia, la adopción de niños por parte de parejas homosexuales, la relaciones sexuales antes del matrimonio o la clonación.

En ese sentido, los resultados de este estudio señalan cómo la edad muestra claramente el cambio social y deja entrever hacia dónde se dirige la religiosidad de la sociedad española. Las personas más jóvenes son las más partidarias de la separación entre Estado y religión, una menor práctica de la religión y un mayor peso de la no necesidad de creer para tener una conducta moral. Los datos indican que las opiniones favorables a la religión y mayor práctica íntima de la religión están más presentes en las mujeres. Por otro lado, la educación no es relevante a la hora de predecir la adopción de una ética civil o religiosa, pero sí para ser partidario de la separación entre Estado y religión y para asumir la autonomía frente al destino. 
Por lo demás, se comprueba una consistencia estructural en torno a los principales componentes considerados de la ética civil. Aquellos que opinan que no es necesario Dios para tener una conducta moral tienen menor probabilidad de considerar la religión como algo relevante en su vida (que la religión es importante en su vida, menor frecuencia de rezo y más contrarios a la presencia de la religión en la política) y mayor probabilidad de considerar que viven en una sociedad moderna. La adopción de estos principios ético-morales tiene una influencia indirecta (a través de la importancia de la religión en sus vidas y la opinión de que España es un país moderno) en cuestiones existenciales que anteponen la creencia en el libre albedrío frente al destino.

Una investigación más amplia sobre la misma fuente de datos permitiría comparar la persistencia de esta ética civil y sus determinantes estructurales con la de otros países de la misma tradición católica en Europa. Así, se podría evaluar su especificidad y ver el grado en el que los continuos intentos de la jerarquía eclesiástica para influir sobre la vida política y social de España tienen efecto. Algo que sí forma parte de la idiosincrasia sociopolítica de este país. Por otro lado, se reconoce la limitación de este estudio para incorporarlo de manera directa a las series sobre el proceso de secularización en España debido a la particularidad de las preguntas empleadas en esta encuesta, que difieren de las incluidas en otros estudios. Sin embargo, esto ha permitido validar mediante mediciones alternativas los hallazgos previos, y testar por primera vez la relación entre la ética civil y la religión en España. Tal como indican los resultados en términos de evolución probable, teniendo en cuenta las conclusiones respecto a la adopción de la ética civil por parte de la juventud y su previsible efecto sobre el cambio social, el presente estudio puede ser la base para futuros estudios longitudinales sobre datos de la misma encuesta en las subsiguientes ediciones. Más aún si tenemos en cuenta que la mayor cualificación educativa de las mujeres también puede provocar un efecto amplificador de la ética civil en España: la relación directa entre educación y opinión favorable a la separación entre religión y Estado puede restar importancia a la mayor presencia de la práctica religiosa y al mayor apego a la tradición por parte de las mujeres en comparación con los hombres.

Para finalizar advertir que, a pesar de basarse en un conjunto limitado de principios, la ética civil no es neutra y puede hacer emerger conflictos de orden político y cultural por el hecho de mantener una posición de superioridad con respecto no solo a las religiones, sino también en relación a otras culturas no occidentales. Desde el punto de vista político, el laicismo es un concepto contiguo al de ética civil y que podría ser incorporado perfectamente al estudio de la secularización; en el sentido de evaluar hasta qué punto se asume en este país la posible adopción de un laicismo liberal (neutralidad del poder político con respecto a la moral civil) o un laicismo republicano que interviene en el ámbito educativo para que lo religioso no anule las capacidades de los ciudadanos. 


\section{REFERENCIAS BIBLIOGRÁFICAS}

Alaminos, A. y C. Penalva. 2008. "La vida cotidiana en la España del Siglo XXI". Pp. 759-809 en La España del Siglo XXI: La Sociedad, vol. 1, editado por S. del Campo y J. F. Tezanos. Madrid: Biblioteca Nueva.

Arroyo, M. 2005. "Religiosidad centrífuga. ¿Un catolicismo sin Iglesia?". Iglesia Viva 222:111-119.

Beck, U. 2009. El Dios personal. La individualización de la religión y el 'espíritu' del cosmopolitismo. Barcelona: Paidós.

Berger, P. L. 2008. "Secularization Falsified." First Thing 180:23-27.

Camacho, J. M. 2008. "Los valores de los españoles". Pp. 811-858 en La España del Siglo XXI: La Sociedad, vol.1, editado por S. del Campo y J. F. Tezanos. Madrid: Biblioteca Nueva.

Casanova, J. 2006. "Rethinking Secularization: A Global Comparative Perspective" The Hedgehog Review 8:7-22.

Castón, P. 2002. "La secularización en la sociedad española". Pp. 41-64 en La sociedad, teoría e investigación empírica: estudios en homenaje a José Jiménez Blanco, editado por J. Iglesias de Ussel. Madrid: CIS.

Comas, D. 2004. "La transición religiosa en España". Pp. 317-352 en Tendencias en identidades, valores y creencias, Séptimo foro sobre tendencias sociales, editado por J. F. Tezanos. Madrid: Sistema.

Cortina, A. y E. Martínez. 1998. Ética. Madrid: Akal.

Davie, G. y D. Hervieu-Léger. 1996. Identities religieuses en Europe. Paris: Le Découverte.

De la Cueva, J. 2007. La secularización conflictiva: España (1898-1931). Madrid: Biblioteca Nueva.

Del Campo, S. y J. F. Tezanos. 2008. "Tendencias e indicadores sociales de la sociedad española". Pp. 903-936 en La España del Siglo XXI: La Sociedad, vol. 1, editado por S. Del Campo y J. F. Tezanos. Madrid: Biblioteca Nueva.

Díaz Salazar, R. 2007. Democracia laica y religión pública. Madrid: Taurus.

Durkheim, E. 1982. Las formas elementales de la vida religiosa. Madrid: Akal.

Elzo, J. 2008a. "La evolución socio-religiosa en España en los últimos 30 años: una aproximación empírica". Pp. 77-96 en El fenómeno religioso: presencia de la religión y de la religiosidad en las sociedades avanzadas, coordinado por E. Bericat. Sevilla: Centro de Estudios Andaluces.

Elzo, J. 2008b. "Religión y religiosidad". Pp. 435-470 en La España del Siglo XXI: La Sociedad, vol. 1, editado por S. del Campo y J. F. Tezanos. Madrid: Biblioteca Nueva.

Elzo, J. 2009. "¿Son los jóvenes españoles diferentes?: Comparación de algunos valores de los jóvenes españoles con los de los jóvenes europeos." Quaderns de la Mediterrània 11:239-244. 
Esteban, V. 2008. "La secularización en entredicho: la revisión de un debate clásico de la sociología". Pp. 299-312 en El fenómeno religioso: Presencia de la religión y de la religiosidad en las sociedades avanzadas, coordinado por E. Bericat. Sevilla: Centro de Estudios Andaluces.

Giner, S. y S. Sarasa. 1992. "Religión, política y modernidad en España." Revista Internacional de Sociología 1:9-60.

González-Anleo, J. 2006. “Jóvenes y religiosidad”. Pp. 241-303 en Jóvenes españoles 2005, editado por J. Elzo y P. González Blasco. Madrid: Fundación SM.

González Blasco, P. 2002. "La religiosidad interior en la España Actual". Pp. 133-174 en La sociedad, teoría e investigación empírica: estudios en homenaje a José Jiménez Blanco, editado por J. Iglesias de Ussel. Madrid: CIS.

Hervieu-Léger. D. et. al. 1992. La religiones degli europei. Fede, cultura religiosa e modernitá in Francia, Italia, Spagna, Gran Bretagna, Germania e Ungheria. Torine: Edizione della Fondazione Giovanni Agnelli.

Jiménez Blanco, J. y J. Estruch. 1972. La secularización en España. Una investigación empírica. Bilbao: Mensajero.

Luckmann, T. 1973. La religión invisible. Salamanca: Sígueme.

Luckmann, T. 1989. "Religión y condición social de la conciencia moderna". Pp. 87-108 en Razón, ética y política, editado por X. Palacios y F. Jarauta. Barcelona: Anthropos.

Mardones, J. M. 1995. "Ética civil y religión. Las aportaciones de la religión a una ética civil en la sociedad de riesgo". Ponencia presentada en el XVII Congreso Internacional de Historia de las Religiones,1995, México.

Megías, E. 2000. Los valores de los españoles y su relación con las drogas. Barcelona: Fundación La Caixa.

Moreno, M. 2001. "El miedo a la libertad religiosa. Autoridades franquistas, católicos y protestantes ante la Ley de 28 de junio de 1967." Anales de Historia Contemporánea 17:351-353.

Pérez-Agote, A. 2007. "El proceso de secularización en la sociedad española." Revista CIDOB d'afers internacionals 77:65-82.

Rawls, J. 1971. A Theory of Justice. Cambridge, Massachusetts: Harvard University Press.

Santiago, J. A. 2005. "Secularización y nacionalismo. Un análisis comparado de los nacionalismos vasco y quebequense". Tesis de doctorado. Facultad de Ciencias Políticas y Sociología. Universidad Complutense. (Disponible en http://eprints.ucm.es/tesis/cps/ucm-t27863.pdf).

Tezanos, J. F. y V. Díaz. 2006. Tendencias Sociales 1995-2006. Once años de cambios. Madrid: Sistema.

United Nations Educational, Scientific and Cultural Organization 1996. Our creative diversity. Report of the world commission on culture and development. Paris: Unesco.

Weber, M. 1987. Ensayos sobre Sociología de la Religión. Madrid: Taurus. 
ANTONIO ALAMINOS CHICA es Doctor en Sociología por la Universidad Complutense de Madrid. Catedrático de Sociología en la Universidad de Alicante. Líneas de investigación en sociología matemática (medición, construcción de índices y modelos), estructura y procesos sociopolíticos comparados, socialización, cambio generacional, migraciones e interculturalidad, comportamiento electoral y prospectiva.

CLEMENTE PENALVA VERDÚ es Doctor en Sociología, profesor del departamento de Sociología II de la Universidad de Alicante. Líneas de investigación: análisis de datos textuales, comunicación y desigualdad y socialización política. Publicaciones recientes: "La imagen de España y Marruecos en la prensa marroquí y española durante el incidente de la isla de Perejil" Revista CIDOB; "Comunicación de masas y violencia estructural" Revista Convergencia

RECIBIDO: $26 / 04 / 2010$

ACEPTADO: $10 / 09 / 2011$

\section{AneXo \\ Nota metodológica}

Para el modelo estructural las variables exógenas son la "edad" $\left(X_{1}\right)$, codificada mediante los años cumplidos en el último cumpleaños, el "género" $\left(X_{2}\right)$ codificada como hombre o mujer según autoclasificación del entrevistado; la "educación" $\left(X_{3}\right)$ expresada según los años cursados de educación formal. La "ideología política" se mide mediante auto ubicación en escala Likert con formato gráfico $\left(Y_{1}\right)$, expresada en el rango entre 1, para indicar la posición ideológica de izquierdas, y 10 para la ubicación derecha. La autoubicación ideológica aparece dependiente del género en el modelo. Así, en la especificación del modelo ejerce una función explicativa cuasi exógena, dado que hemos considerado significativo teóricamente controlar mediante la variable género su efecto sobre otras variables.

El resto de las variables, que forman parte de la explicación como endógenas son: La creencia en el control de la propia vida o su determinación por circunstancias externas al individuo se recoge mediante la cuestión "El éxito en la vida está determinado por fuerzas fuera de nuestro control" $\left(Y_{2}\right)$; ofreciendo como opciones de respuesta: "completamente de acuerdo", "bastante de acuerdo", "bastante en desacuerdo", "completamente en desacuerdo". La valoración de la participación de los líderes religiosos en la vida pública se mide mediante la afirmación "La influencia de los líderes religiosos es" $\left(\mathrm{Y}_{3}\right)$, con las opciones de "muy positiva para el país", "bastante positiva para el país", "bastante negativa para el país" o "muy negativa para el país". La valoración de las consecuencias de la intervención de los líderes religiosos en la sociedad, nos refiere directamente a la distinción entre las fuentes religiosas o cívicas de las éticas ciudadanas. La cuestión central se recoge en la pregunta "No es necesario creer en Dios para poseer valores 
morales y ser honesto" $\left(\mathrm{Y}_{4}\right)$. La respuesta sobre si es necesario o no es necesario se refiere a dos perspectivas éticas: una religiosa y otra cívica. En la misma línea argumental, se pregunta por la relación entre el Estado y la religión. Aquí, el eje se desplaza desde la religión, la sociedad y sus valores hacia un tercer elemento: la política y el Estado ("la religión es un asunto de fe personal y debe mantenerse separada de la política gubernamental", $Y_{5}$ ), con las opciones de respuesta: "completamente desacuerdo", "bastante desacuerdo", "bastante de acuerdo", "completamente de acuerdo". En cuanto a costumbres, normas y usos sociales: "Nuestro modo tradicional de vida permanece fuerte (o se está perdiendo)" $\left(\mathrm{Y}_{6}\right)$. Para caracterizar el grado de religiosidad se pregunta sobre comportamiento ("Con qué frecuencia reza", $Y_{7}$ ): "varias veces al día", "alguna vez al día", "varias veces durante la semana", "alguna vez a la semana o menos", "nunca". Con carácter de resumen aparece la pregunta de valoración subjetiva "Cuánta importancia tiene la religión en su vida" $\left(\mathrm{Y}_{8}\right)$, con sus opciones ordinales de respuesta del entrevistado: "mucha", "alguna", "no demasiada", "ninguna".

Cuadro 1.

Especificación del modelo.

$$
\begin{aligned}
& \mathrm{Y}_{1}=\gamma_{12} \mathrm{X}_{2}+\zeta_{1} \\
& \mathrm{Y}_{2}=\beta_{26} \mathrm{Y}_{6}+\beta_{28} \mathrm{Y}_{8}+\gamma_{23} \mathrm{X}_{3}+\zeta_{2} \\
& \mathrm{Y}_{3}=\beta_{32} \mathrm{Y}_{2}+\beta_{34} \mathrm{Y}_{4}+\beta_{36} \mathrm{Y}_{6}+\beta_{38} \mathrm{Y}_{8}+\zeta_{3} \\
& \mathrm{Y}_{4}=\beta_{41} \mathrm{Y}_{1}+\gamma_{41} \mathrm{X}_{1}+\gamma_{42} \mathrm{X}_{2}+\zeta_{4} \\
& \mathrm{Y}_{5}=\beta_{54} \mathrm{Y}_{4}+\beta_{58} \mathrm{Y}_{8}+\gamma_{51} \mathrm{X}_{1}+\gamma_{53} \mathrm{X}_{3}+\zeta_{5} \\
& \mathrm{Y}_{6}=\beta_{64} \mathrm{Y}_{4}+\beta_{67} \mathrm{Y}_{7}+\zeta_{6} \\
& \mathrm{Y}_{7}=\beta_{78} \mathrm{Y}_{8}+\gamma_{71} \mathrm{X}_{1}+\zeta_{7} \\
& \mathrm{Y}_{8}=\beta_{81} \mathrm{Y}_{1}+\beta_{84} \mathrm{Y}_{4}+\gamma_{81} \mathrm{X}_{1}+\gamma_{82} \mathrm{X}_{2}+\zeta_{8}
\end{aligned}
$$


Cuadro 2.

Modelo estructural ajustado.

$\mathrm{Y}_{1}=-.16 \mathrm{X}_{2}+.98$
(.11) (.10)
$\mathrm{R}^{2}=.024$

$-3.53 \quad 15.75$

$\mathrm{Y}_{2}=.18 \mathrm{Y}_{6}+.10 \mathrm{Y}_{8}+.13 \mathrm{X}_{3}+.94$

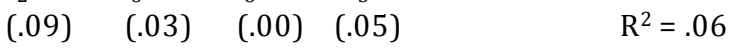

$\begin{array}{llll}4.1 & 2.25 & 3 & 15.75\end{array}$

$\mathrm{Y}_{3}=.18 \mathrm{Y}_{2}+.25 \mathrm{Y}_{4}+.09 \mathrm{Y}_{6}+.20 \mathrm{Y}_{8}+.8$
$(.02)$
$(.04)$
(.05)
(.02) (.01)
$\mathrm{R}^{2}=.20$

$\begin{array}{lllll}4.4 & 5.6 & 2.13 & 4.5 & 15.7\end{array}$

$\mathrm{Y}_{4}=-.14 \mathrm{Y}_{1}-.13 \mathrm{X}_{1}+.22 \mathrm{X}_{2}+.9$

$\begin{array}{lllll}(.01) & (.00) & (.03) & (.01) & \mathrm{R}^{2}=.09\end{array}$

$\begin{array}{llll}-3.3 & -3.1 & 5.1 & 15\end{array}$

$\mathrm{Y}_{5}=.14 \mathrm{Y}_{4}+.15 \mathrm{Y}_{8}-.19 \mathrm{X}_{1}+.13 \mathrm{X}_{3}+.93$

$\begin{array}{llllll}(0.02) & (.00) & (.00) & (.00) & (.00) & \mathrm{R}^{2}=.06\end{array}$

$\begin{array}{lllll}3 & 3.1 & 3.6 & 2.5 & 15\end{array}$

$\mathrm{Y}_{6}=.33 \mathrm{Y}_{4}+-.32 \mathrm{Y}_{7}+.84$

$\begin{array}{llll}(.04) & (.01) & (.00) & \mathrm{R}^{2}=.16\end{array}$

$\begin{array}{lll}7.7 & -7.6 & 15\end{array}$

$\mathrm{Y}_{7}=.74 \mathrm{Y}_{8}-.10 \mathrm{X}_{1}+.40$

$\begin{array}{llll}(.03) & (.00) & (.04) & \mathrm{R}^{2}=.60\end{array}$

$\begin{array}{lll}25.2 & -3.45 & 15\end{array}$

$\mathrm{Y}_{8}=-.18 \mathrm{Y}_{1}+.17 \mathrm{Y}_{4}-.24 \mathrm{X}_{1}+.22 \mathrm{X}_{2}+.78$
$(.03)$
(.09)
(.00)
(.08)
$(.05)$
$\mathrm{R}^{2}=.22$

$-4.3$

$4.1 \quad-5.97$

5.38

15 
Tabla 3.

Efectos directos estandarizados.

\begin{tabular}{lcl}
\hline & & \\
Variable explicativa & $\begin{array}{c}\text { Coeficientes } \\
\text { estandarizados }\end{array}$ & \multicolumn{1}{l}{ Variable explicada } \\
\hline Edad & -.13 & Ética civil o religiosa \\
Ubicación ideológica & -.14 & Ética civil o religiosa \\
Género & .22 & Ética civil o religiosa \\
Género & -.16 & Ubicación ideológica \\
Ubicación ideológica & -.18 & Importancia religión en su vida \\
Edad & -.24 & Importancia religión en su vida \\
Género & .22 & Importancia religión en su vida \\
Edad & -.10 & Frecuencia de rezo \\
Edad & -.19 & Separación religión y estado \\
Educación & .13 & Separación religión y estado \\
Educación & .13 & Destino o libre albedrío \\
Ética civil o religiosa & .33 & Sociedad moderna o tradicional \\
Ética civil o religiosa & .25 & Intervención líderes religiosos en la sociedad \\
Ética civil o religiosa & .14 & Separación religión y estado \\
Ética civil o religiosa & .17 & Importancia religión en su vida \\
Importancia religión en su vida & .20 & Intervención líderes religiosos en la sociedad \\
Importancia religión en su vida & .10 & Destino o libre albedrio \\
Importancia religión en su vida & .15 & Separación religión y estado \\
Importancia religión en su vida & .74 & Frecuencia de rezo \\
Sociedad moderna o tradicional & .90 & Intervención líderes religiosos en la sociedad \\
Sociedad moderna o tradicional & .18 & Destino o libre albedrío \\
Destino o libre albedrío & .18 & Intervención líderes religiosos en la sociedad \\
Frecuencia de rezo & -.32 & Sociedad moderna o tradicional \\
\hline
\end{tabular}

Fuente: Elaboración propia sobre coeficientes del modelo especificado 
Tabla 4.

Efectos totales estandarizados.

\begin{tabular}{lcccc}
\hline & Género & Edad & Educación & Ideología \\
\hline Estado/Religión & 0.08 & 0.14 & 0.13 & -0.05 \\
Ética civil/ religiosa & 0.24 & -0.13 & -- & -0.14 \\
Líderes religiosos & 0.12 & -0.08 & 0.02 & -0.08 \\
Modernidad/tradicional & 0.01 & 0.05 & -- & -- \\
Importancia religión & 0.29 & -0.26 & -- & -0.20 \\
Frecuencia de rezo & 0.22 & -0.30 & -- & -0.15 \\
Destino / Libre albedrío & 0.03 & -0.02 & 0.13 & -0.02 \\
& & & & \\
\hline
\end{tabular}

